\title{
PENYULUHAN MENGENAI OPTIMALISASI UPAYA PELESTARIAN PENYU DI PANTAI MAPAK INDAH, KELURAHAN JEMPONG BARU, KECAMATAN SEKARBELA
}

\author{
Optimizing Turtle Conservation Efforts Through Conselling And Mentoring At Mapak Indah \\ Beach, Jempong Baru Village, Sekarbela District
}

\section{Ibadur Rahman*, Chandrika Eka Larasati, Ayu Adhita Damayanti, Soraya Gigentika}

Program Studi Ilmu Kelautan Universitas Mataram

Jalan Pendidikan No. 37 Mataram, Nusa Tenggara Barat, 83125 Indonesia

*Alamat Korespondensi: ibadur.rahman@unram.ac.id

(Tanggal Submission: 4 Februari 2021, Tanggal Accepted : 5 April 2021)

\begin{abstract}
Keyword: Abstract :
pantai mapak indah, penyu, pelestarian Penyu merupakan salah satu biota laut yang dilindungi karena keberadaannya sudah terancam punah, terutama untuk beberapa jenis penyu, yaitu penyu belimbing (Dermochelys coriacea), penyu kemp's ridley (Lepidochelys kempii) dan penyu sisik (Eretmochelys imbricata). Terbatasnya informasi yang diterima masyarakat penyu menyebabkan upaya pelestarian penyu dilakukan secara tradisional sehingga tidak berjalan optimal, salah satunya yang terjadi di Pantai Mapak Indah, Kelurahan Jempong Baru, Kecamatan Sekarbela, Kota Mataram. Kegiatan pengabdian kepada masyarakat ini bertujuan untuk memberikan penyuluhan dan pendampingan kepada masyarakat, khususnya Kelompok Pelestari Penyu Pantai Mapak Indah mengenai bentuk-bentuk upaya pelestarian penyu yang baik dan benar. Berdasarkan pengamatan dan hasil wawancara selama kegiatan pengabdian ditemukan beberapa kegiatan dalam upaya pelestarian penyu di Pantai Mapak Indah yang dirasa kurang sesuai sehingga perlu untuk diluruskan dan diperbaiki. Rekomendasi yang diberikan dalam kegiatan pengabdian kepada masyarakat ini antara lain terkait dengan lokasi pengambilan telur, desain sarang peneluran, waktu pelepasan tukik, pemberian pakan tukik, dan keramaian akibat tingginya aktivitas warga di lokasi pelestarian penyu. Masyarakat menyambut baik rekomendasi yang diberikan dan berharap dapat mendapatkan pendampingan secara kontinu sehingga kegiatan pelestarian penyu dapat semakin dioptimalkan. Dengan demikian, kegiatan penyuluhan ini sangat bermanfaat bagi masyarakat khususnya pengelola wisata penyu Pantai Mapak Indah karena menambah wawasan mereka mengenai praktek konservasi penyu yang baik dan benar.
\end{abstract}

Panduan sitasi / Citation guidance (APPA $7^{\text {th }}$ edition) :

Rahman, I., Larasati, C. E., Damayanti, A. A., Gigentika, S. (2021). Penyuluhan Mengenai Optimalisasi Upaya Pelestarian Penyu Di Pantai Mapak Indah, Kelurahan Jempong Baru, Kecamatan Sekarbela. Jurnal Abdi Insani Universitas Mataram, 8 (1), 39-46. http://doi.org/10.29303/abdiinsani.v8i1.373. 


\section{PENDAHULUAN}

Penyu atau kura-kura laut (sea turtle) merupakan salah satu biota laut eksotik yang keberadannya sangat dilindungi karena sudah terancam punah (Nurapriyanto, 2003; Hardiono et al., 2012) terutama jenis penyu belimbing (Dermochelys coriacea), penyu kemp's ridley (Lepidochelys kempii) dan penyu sisik (Eretmochelys imbricata) (IUCN, 2013). Menyadari hal tersebut, baik pemerintah, lembaga swasta, maupun masyarakat secara swadaya merasa terdorong untuk melakukan upaya pelestarian penyu. Adapun upaya yang dilakukan antara lain: menerbitkan peraturan yang melarang penangkapan, mengkonsumsi ataupun memperjualbelikan telur, daging, atau bagian tubuh penyu lainnya (Undang-Undang Republik Indonesia Nomor 5 Tahun 1990 tentang Konservasi Sumber Daya Alam Hayati dan Ekosistemnya, Pasal 21 Ayat (2) Huruf e., 1990); upaya rehabilitasi habitat penyu (Ngatno, 1999); upaya perawatan penyu yang ditemukan dalam keadaan sakit (Indrabayu et al., 2018); maupun upaya zonasi habitat penyu (Budiantoro, 2017) guna meningkatkan kelulushidupan penyu yang terancam punah.

Terbatasnya informasi yang diterima masyarakat menyebabkan upaya pelestarian penyu dilakukan dengan cara tradisional sehingga tidak berjalan optimal. Terkadang, hal yang diyakini masyarakat dapat melestarikan keberadaan penyu ternyata justru dapat membahayakan penyu tersebut. Misalnya, masyarakat membuat pagar beton dengan maksud menghalangi hewan pemangsa memakan telur penyu, namun praktek tersebut ternyata dapat menghalangi anakan penyu (tukik) untuk segera menuju ke laut setelah menetas. Atau, kebiasaan masyarakat yang memberikan makan penyu berupa kulit ayam akan dapat mengganggu insting alamiah penyu dalam mencari makan, karena di alam hewan yang dimangsa penyu yaitu ikan, udang atau kepiting.

Kesalahpahaman masyarakat dalam merawat atau membesarkan penyu yang sudah terjadi selama ini perlu segera ditangani, sehingga upaya pelestarian penyu dapat berjalan optimal dan tingkat kelangsungan hidup penyu dapat semakin ditingkatkan. Kegiatan pengabdian kepada masayarakat ini diharapkan dapat memberikan pemahaman yang menyeluruh kepada masyarakat, sehingga praktek-praktek yang dapat mengancam kelestarian penyu akibat ketidaktahuan masyarakat dapat dihindari. Di samping itu, pemahaman mengenai aspek-aspek biologi penyu diharapkan dapat membuat masyarakat semakin sadar bahwa upaya pelestarian penyu tidak hanya dilakukan berdasarkan perilaku penyu yang tampak secara kasat mata, namun juga perlu melihat tingkat laku dan sifat naluri alami penyu yang tidak tampak. Dengan pemahaman tersebut, diharapkan upaya pelestarian penyu dapat berjalan semakin optimal.

\section{METODE KEGIATAN}

Kegiatan pengabdian kepada masyarakat ini dilakukan pada bulan Juli-September 2020 di kawasan Pantai Mapak Indah, Keluarahan Jempong Baru, Kecamatan Sekarbela, Kota Mataram, meliputi kegiatan penyuluhan dan pendampingan mengenai optimalisasi upaya pelestarian penyu.

Kegiatan pengabdian kepada masyarakat ini dibagi menjadi beberapa tahapan :

1) Survei lokasi dan perizinan

Survei lokasi meliputi kegiatan peninjauan ke lokasi pengabdian, menggali informasi tentang permasalahan yang dihadapi mitra menggunakan metode wawancara langsung dengan masyarakat, dan studi literatur terhadap kegiatan penelitian atau pengabdian yang pernah dilakukan sebelumnya di Pantai Mapak Indah, Kelurahan Jempong Baru, Kecamatan Sekarbela, 
Kota Mataram. Sedangkan perizinan meliputi kegiatan surat-menyurat, permohonan izin kepada pihak berwenang untuk menyelenggarakan kegiatan pengabdian kepada masyarakat.

2) Persiapan kegiatan penyuluhan

Kegiatan persiapan meliputi penyiapan materi penyuluhan, baik berupa brosur, spanduk, dan media informasi lainnya, dan persiapan sarana dan prasarana yang digunakan pada kegiatan pengabdian.

3) Survei dan observasi lapangan

Kegiatan survei dan observasi dilakukan untuk mengetahui kondisi sarana prasarana yang dimiliki masyarakat dalam upaya pelestarian penyu Pantai Mapak Indah, dan menggali informasi terkait hambatan dan kendala yang dihadapi. Hasil wawancara dan observasi tersebut akan menjadi bahan materi dalam kegiatan penyuluhan.

4) Penyuluhan mengenai optimalisasi upaya pelestarian penyu.

Kegiatan penyuluhan meliputi penyampaian materi dan diskusi mengenai bentuk dan upaya pelestarian penyu yang baik dan benar, dengan menghadirkan pakar terutama mengenai biologi dan konservasi penyu, sehingga kegiatan pelestarian penyu yang dilakukan Kelompok Pelestari Penyu Pantai Mapak Indah dapat berjalan optimal.

5) Evaluasi

Kegiatan evaluasi diperlukan untuk mengetahui seberapa efektif kegiatan pengabdian yang telah dilakukan, dan seberapa besar dampak yang diberikan dalam meningkatkan kesadaran masyarakat mengenai bentuk kegiatan apa yang dapat dilakukan untuk meningkatkan upaya pelestarian penyu di Pantai Mapak Indah.

\section{HASIL DAN PEMBAHASAN}

Kawasan wisata penyu Pantai Mapak Indah merupakan salah satu destinasi wisata dengan panorama pantai di Kota Mataram. Pantai ini semakin terkenal sejak dicanangkan sebagai kawasan eduwisata penyu oleh sebagian masyarakat lokal yang menamai diri mereka sebagai Kelompok Pelestari Penyu Mapak (KP2M). Adapun kegiatan yang dilakukan oleh kelompok ini antara lain: memindahkan sarang peneluran penyu ke lokasi peneluran buatan, perawatan tukik penyu sebelum dilepas ke laut, mengedukasi masyarakat khususnya siswa sekolah terkait upaya pelestarian penyu, dan pemberdayaan masyarakat dalam mendukung terbentuknya kawasan wisata penyu Pantai Mapak Indah.

Berdasarkan pengamatan di lapangan dan wawancara yang dilakukan terhadap Kelompok Pelestari Penyu Pantai Mapak Indah, berbagai bentuk upaya pelestarian penyu telah dilakukan di Pantai Mapak, di antaranya yaitu:

1. Telur penyu yang tersebar di sejumlah lokasi peneluran penyu di Pulau Lombok telah dipindahkan ke tempat penetasan yang relatif lebih aman dan terlindungi dari hewan pemangsa dan juga manusia.

2. Tersedia tempat (berupa bak penampungan) untuk merawat dan memelihara tukik (anakan penyu) yang baru menetas agar lebih siap sebelum di lepas ke laut. 


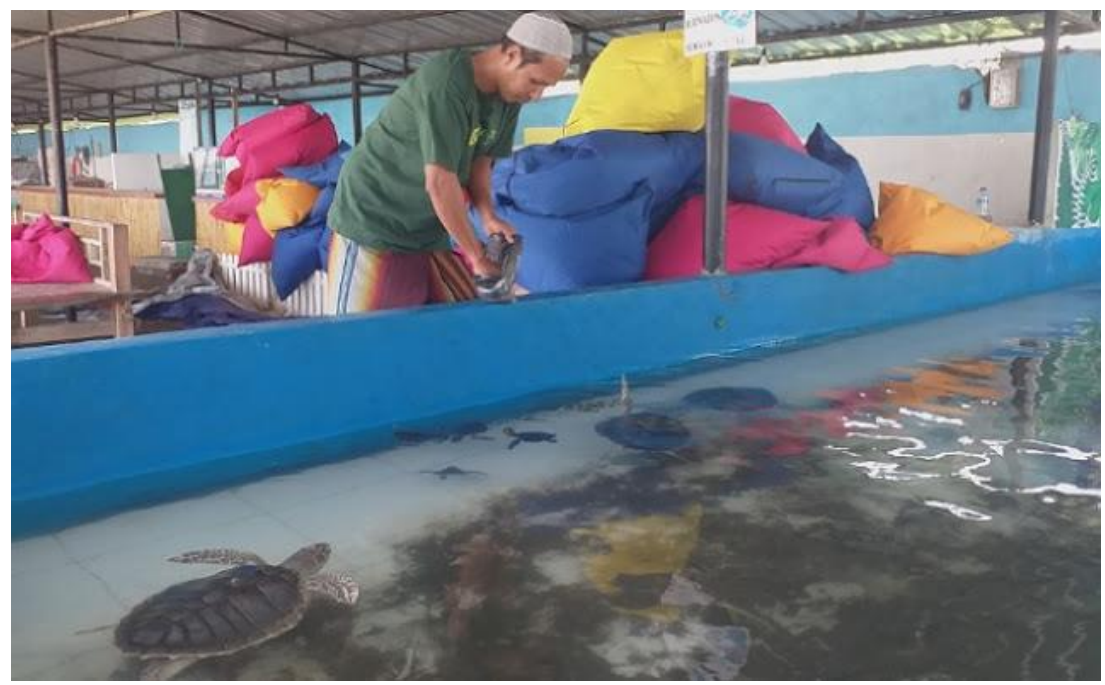

Gambar 1. Bak penampungan tukik dan penyu sebelum dilepas ke laut (https://www.mandalikapost.com/)

3. Tersedia sarana edukasi bagi pelajar/siswa, mahasiswa dan masyarakat untuk mengenal kehidupan, tingkah laku, kebiasaan dan karakteristik habitat penyu. Kegiatan ini sangat bermanfaat untuk menambah wawasan dan kesadaran masyarakat dalam upaya melestarikan penyu.

4. Masyarakat sekitar telah diberdayakan untuk ikut terlibat dalam pengembangan kawasan wisata penyu di Pantai Mapak, baik sebagai pemelihara penyu, penyedia barang atau jasa wisata, kuliner, petugas kebersihan, ataupun yang lainnya.

Kegiatan pelestarian penyu harus dilakukan dengan memperhatikan berbagai hal menyangkut karakteristik habitat, tingkah laku, kebiasaan dan preferensi makan dan pola adaptasinya sehingga upaya pelestarian penyu berjalan optimal dan dapat meningkatkan kelulushidupan penyu di alam. Terdapat beberapa kegiatan yang telah dilakukan dalam upaya pelestarian penyu Pantai Mapak yang diduga dapat menghambat keberhasilan pelestarian penyu, yaitu:

1. Sebagian besar telur yang ditetaskan di Pantai Mapak tersebut berasal dari berbagai lokasi peneluran penyu yang berjarak cukup jauh. Hal ini dikhawatirkan dapat merubah kondisi sarang peneluran, misalnya suhu, kelembaban dan tekstur sedimen dari kondisi aslinya, sehingga dapat nengurangi tingkat keberhasilan penetasan telur penyu.

2. Sarang penetasan penyu yang telah dipindahkan dari sarang aslinya tidak dikontrol dengan baik, sehingga keberhasilan penetasan penyu menjadi kurang optimal.

3. Lokasi sekitar sarang peneluran penyu dibuat dari bahan beton semi permanen. Meskipun dinding beton tersebut awalnya dimaksudkan agar telur semakin terlindungi dari serangan hewan pemangsa atau manusia, namun dikhawatirkan dinding beton tersebut dapat menghalangi tukik penyu yang baru menetas untuk langsung masuk ke laut. Kondisi tersebut dikhawatirkan akan berpengaruh terhadap insting penyu untuk mengenali lokasi daerah penelurannya. 

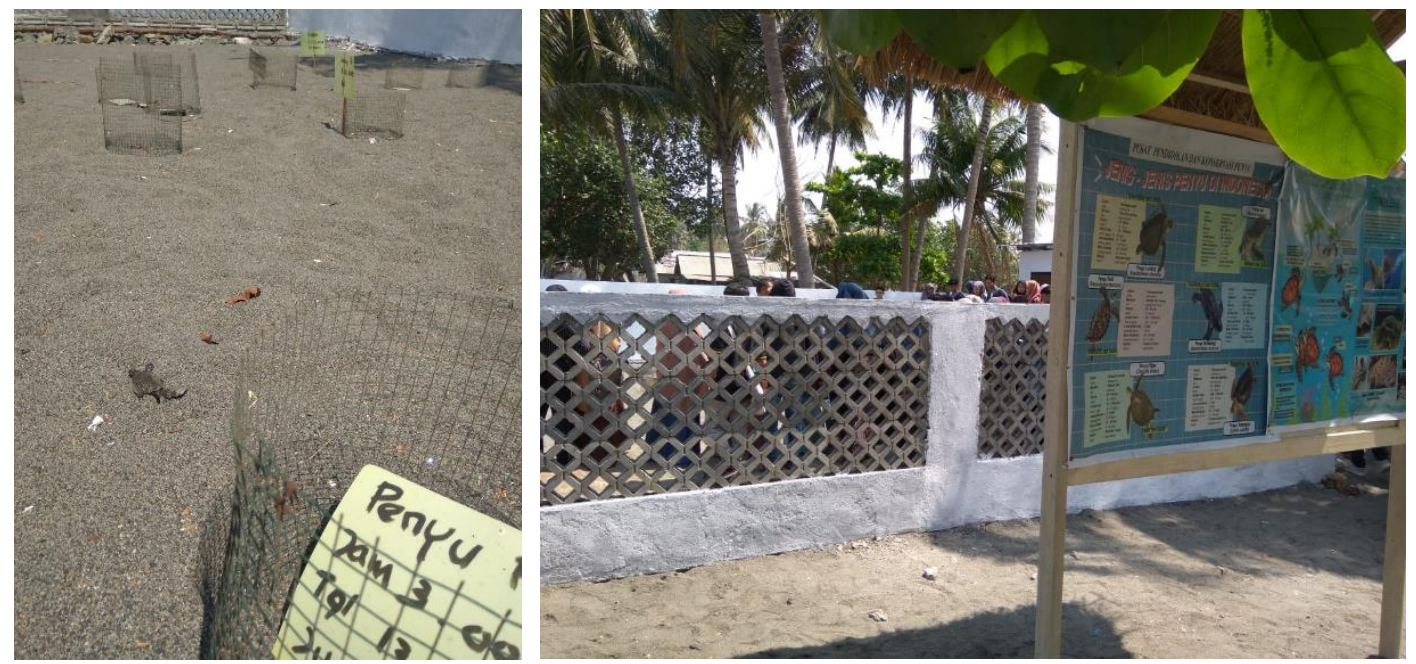

Gambar 2. Kondisi sarang peneluran penyu yang diberi pagar beton semi permanen (dokumentasi pribadi)

4. Tukik penyu yang baru menetas tidak segera dilepas ke laut, namun dipelihara dahulu dalam wadah penampungan dengan tujuan agar tukik lebih siap sebelum dilepas ke laut. Tukik penyu yang baru menetas memiliki bobot yang ringan dan cenderung mengapung di permukaan perairan. Hal tersebut menjadikan tukik penyu sangat rawan dimangsa burung-burung pemakan daging. Di samping itu, tukik yang dirawat di bak penampungan sebelum dilepas ke laut dapat mengeliminasi tukik-tukik yang cacat atau berpenyakit, sehingga kelulushidupan tukik penyu di laut dapat dioptimalkan. Namun, hal tersebut dikhawatirkan dapat mengganggu insting "geomagnetic" penyu dalam mengenali daerah penelurannya mengingat penyu merupakan biota yang memiliki ciri khas bertelur di tempatnya dulu ditetaskan (Lohmann et al., 2008).

5. Tukik penyu yang baru menetas biasa diberi makanan berupa kulit ayam untuk memenuhi kebutuhan nutrisinya. Pada kenyataannya, hal tersebut dapat mengganggu insting alamiah penyu untuk mencari makan, karena di lautan mereka biasa memakan ikan, udang atau kepiting.

6. Pelepasan tukik ke laut dilakukan setiap saat, terutama pada pagi dan siang hari saat banyak wisatawan yang berminat untuk terlibat dalam kegiatan pelepasan penyu.

7. Terdapat banyak aktivitas masyarakat di sekitar lokasi penetasan penyu, seperti: kegiatan lalu lintas kapal nelayan, wisatawan yang berenang di pantai, dan sejumlah tempat wisata kuliner.

Melihat fenomena tersebut di atas, maka dirasa perlu untuk memberikan sedikit masukan kepada masyarakat dan Kelompok Pelestari Penyu Pantai Mapak Indah sehingga kegiatan pelestarian penyu yang telah dilakukan selama ini dapat lebih optimal dan meningkatkan kelulushidupan penyu di alam.

Adapun masukan yang diberikan dalam rangka meningkatkan upaya pelestarian penyu di Pantai Mapak Indah, antara lain:

1. Sebaiknya telur yang akan ditetaskan berasal dari lokasi peneluran yang tidak terlalu jauh sehingga tidak merubah kondisi telur dan sarang peneluran. Selain itu, kondisi sarang yang telah direlokasi perlu dikontrol secara berkesinambungan agar dapat disesuaikan dengan kondisi ideal sarang peneluran. Kondisi sarang peneluran yang ideal akan dapat meningkatkan keberhasilan penetasan. Afifah et al. (2019) menyatakan bahwa suhu udara, suhu substrat dan kadar air substrat mempengaruhi laju inkubasi telur penyu. Semakin tinggi suhu semakin cepat laju 
inkubasi. Hamino et al. (2021) menambahkan bahwa kisaran suhu pasir yang dibutuhkan untuk keberhasilan penetasan telur penyu adalah $25-35^{\circ} \mathrm{C}$ dengan suhu optimal $29^{\circ} \mathrm{C}$.

2. Kondisi sarang peneluran dan penetasan yang terbuat dari bahan beton semi permanen (Gambar 2.) dapat menghalangi tukik penyu yang baru menetas untuk masuk menuju ke laut. Secara alami, tukik akan segera menuju ke laut setelah menetas mengikuti insting alamiahnya. Ketika tukik terhalangi untuk mengikuti insting alamiahnya, dikhawatirkan bakat alamiahnya tersebut dapat terganggu, sehingga nantinya penyu tersebut akan mengalami kesulitan untuk bertahan hidup di alam dan menemukan lokasi peneluran yang sesuai.

3. Pemberian pakan tukik penyu sebaiknya disesuaikan dengan kebiasaan dan preferensi makannya di alam, yaitu: beberapa jenis moluska, krustacea dan makroplankton (Gerosa et al., 2001). Pemberian pakan berupa kulit ayam dikhawatirkan dapat mengganggu pola makan penyu setelah dilepas di alam, karena pakan berupa kulit ayam berbeda dengan makanan penyu di alam berupa ikan, kepiting atau udang.

4. Pelepasan tukik penyu ke laut sebaiknya dilakukan pada saat sore atau malam hari ketika paparan sinar matahari tidak terlalu tinggi dan jumlah kunjungan wisatawan dan aktivitas manusia sudah mulai berkurang. Penyu merupakan hewan yang cukup peka terhadap cahaya dan kebisingan, sehingga waktu sore atau malam hari merupakan waktu yang tepat untuk melepas tukik penyu ke laut. Pratama et al. (2020) menjelaskan bahwa pelepasan tukik sebaiknya dilakukan pada waktu pagi hari (05.00-06.30) atau sore hari (16.00-17.30), untuk menjaga agar tukik tidak mudah dimangsa oleh predator, dan kondisi pantai cenderung lebih sepi.

5. Pelepasan tukik penyu ke laut sebaiknya dilakukan sesegera mungkin setelah tukik menetas dengan memperhatikan tingkat kesehatan penyu tersebut. Penyu yang sakit atau memiliki kelainan bawaan sebaiknya dirawat terlebih dahulu, sedangkan tukik yang sehat sebaiknya segera dilepaskan ke laut sehingga tidak kehilangan kemampuan "geo-magnetic" penyu dalam mengenali lokasi penelurannya. Firliansyah et al. (2017) menyatakan bahwa pembesaran tukik di penangkaran dapat merubah sifat alamiah tukik sehingga saat dilepas ke laut tukik akan mengalami kebingungan dan sulit mencari makan sendiri.

6. Lokasi sarang penetasan telur penyu sebaiknya berada jauh dari pusat kerumunan dan aktivitas warga. Tidak dipungkiri, keberadaan penyu sebagai ikon wisata Pantai Mapak Indah telah menjadi magnet yang menarik kunjungan wisatawan dan pengusaha untuk berinvestasi terutama wisata kuliner. Kunjungan wisatawan tersebut akan semakin meningkatkan keramaian yang sangat bertolak belakang dengan kehidupan penyu yang menyukai kondisi tenang dan tidak bising. 


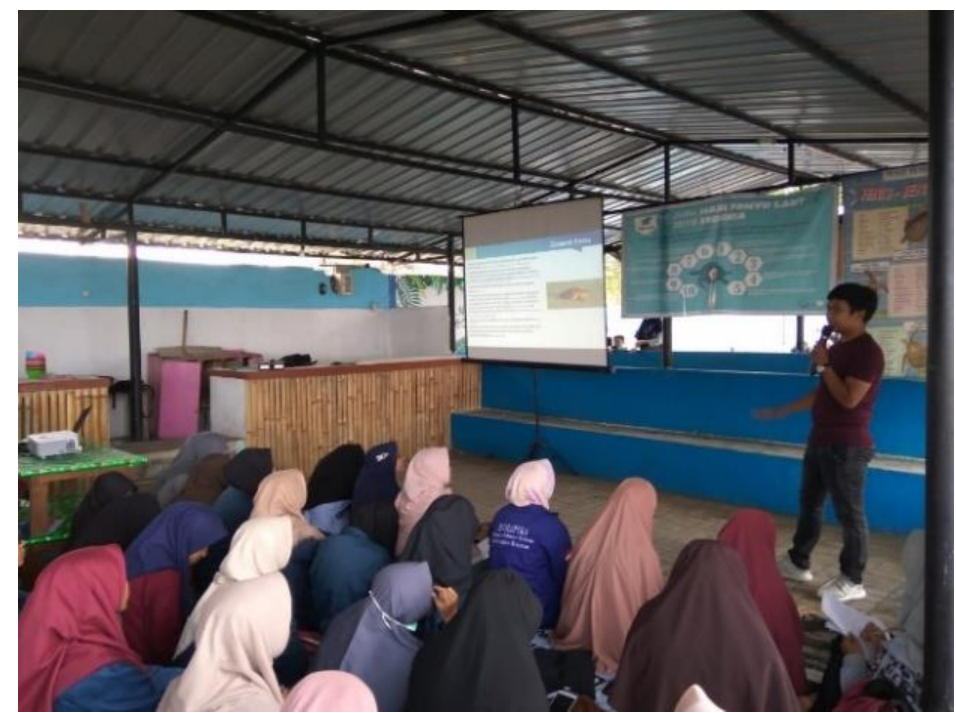

Gambar 3. Penyuluhan mengenai optimalisasi upaya pelestarian penyu di Pantai Mapak Indah (dokumentasi pribadi)

Di samping masukan terkait kegiatan yang sudah berjalan/dilakukan, terdapat pula beberapa masukan mengenai kegiatan yang belum ada dan penting untuk dilakukan guna meningkatkan upaya pelestarian penyu, yaitu dengan menjaga kebersihan lingkungan lokasi peneluran dari sampah, terutama sampah plastik yang seringkali termakan oleh penyu atau tersangkut sirip penyu sehingga menghambat penyu bergerak bahkan dapat menyebabkan kematian.

\section{KESIMPULAN DAN SARAN}

Melalaui kegiatan pengabdian kepada masyarakat berupa kegiatan penyuluhan mengenai optimalisasi upaya pelestarian penyu di Pantai Mapak Indah ini, masyarakat khususnya Kelompok Pelestari Penyu Pantai Mapak Indah telah mendapatkan informasi dan pemahaman mengenai bentukbentuk upaya pelestarian penyu yang baik dan benar. Kekeliruan dalam tata kelola kegiatan pelestarian penyu yang telah terjadi sebelumnya akibat minimnya akses informasi, dapat diperbaiki sehingga upaya pelestarian penyu dapat berjalan optimal dan tingkat kelulushidupan penyu di alam akan semakin tinggi.

Upaya pelestarian penyu yang dilakukan tanpa mempertimbangkan aspek pola hidup, tingkah laku, karakteristik habitat dan kebiasaan makan penyu, selain tidak dapat berjalan optimal praktek tersebut berpotensi menghambat kelangsungan hidup penyu, bahkan berakibat pada kematian. Upaya pelestarian penyu harus dilakukan secara bersama, melibatkan semua stake holder, baik pemerintah, swasta, akademisi dan juga masyarakat sehingga dapat berjalan optimal.

\section{UCAPAN TERIMAKASIH}

Penulis mengucapkan terimakasih kepada Kelompok Pelestari Penyu Pantai Mapak Indah yang telah memberikan izin kepada Tim Pengabdian Kepada Masyarakat Universitas Mataram untuk memberikan penyuluhan dan pendampingan dalam rangka meningkatkan upaya pelestarian penyu di Pantai Mapak Indah. Juga kepada Bapak Muhammad Soimin, M.Sc yang telah memberikan materi penyuluhan dan memberikan berbagai masukan terkait pengelolaan kegiatan pelestarian penyu di Pantai Mapak Indah, serta mahasiswa program studi Budidaya Perairan yang ikut terlibat dan membantu terlaksananya kegiatan ini. 


\section{DAFTAR PUSTAKA}

Afifah, A. N., Sabila, F., \& Hardi, O. S. (2019). Analisis Karakteristik Habitat Penyu Sisik Taman Nasional Kepulauan Seribu, Pulau Pramuka, Kabupaten Kepulauan Seribu, Provinsi DKI Jakarta. Jurnal Siliwangi, 5(1), 23-27.

Budiantoro, A. (2017). Zonasi Pantai Pendaratan Penyu di Sepanjang Pantai Bantul. Jurnal Riset Daerah. Edisi Khusus Tahun.

Firliansyah, E., Kusrini, M. D., \& Sunkar, A. (2017). Pemanfaatan dan Efektivitas Kegiatan Penangkaran Penyu di Bali bagi Konservasi Penyu. Journal of Tropical Biodiversity and Biotechnology, 2(1), 21. https://doi.org/10.22146/jtbb.25690

Gerosa, G., Aureggi, M., \& others. (2001). Sea turtle handling guidebook for fishermen--teaching book. UNEP/MAP RAC/SPA, Tunis, Tunisia.

Hamino, T. Z. A. E., Parawangsa, I. N. Y., Sari, L. A., \& Arsad, S. (2021). Efektifitas Pengelolaan Konservasi Penyu di Education Center Serangan, Denpasar Bali Turtle Conservation and Effectiveness of Sea Turtle Conservation Management at Conservation and Education Center of Serangan, Denpasar Bali the Turtle Pendahuluan Penyu. 10(February).

Hardiono, B. E., Redjeki, S., \& Wibowo, E. (2012). Pengaruh Pemberian Udang Ebi Dengan Konsentrasi Yang Berbeda Terhadap Pertumbuhan Tukik Penyu Lekang (Lepidochelys olivacea) Di Pantai Samas, Bantul. Journal Of Marine Research, 1(2), 67-72.

https://www.mandalikapost.com/2020/02/pantai-penyu-mapak-indah-jadi-destinasi.html (diaskes tanggal 2 April 2021)

Indrabayu, Areni, I. S., Nurtanio, I., Ilham, A. A., \& Yohannes, C. (2018). Peningkatan Kapasitas Keterampilan Teknologi Informasi Bagi Pengelola Komunitas Sahabat Penyu. JURNAL TEPAT: Applied Technology Journal for Community Engagement and Services, 1(2), 99-104. https://doi.org/10.25042/jurnal_tepat.v1i2.20

International Union for Conservation of Nature (IUCN), I. U. (2013). IUCN red list of threatened species.

Lohmann, K. J., Luschi, P., \& Hays, G. C. (2008). Goal navigation and island-finding in sea turtles. Journal of Experimental Marine Biology and Ecology, 356(1), 83-95. https://doi.org/https://doi.org/10.1016/j.jembe.2007.12.017

Ngatno, N. (1999). Evaluasi Program Rehabilitasi Penyu (Kasus Di Teiuk Penyu Kabupaten Cilacap).

Nurapriyanto. (2003). Perburuan Penyu di Kawasan Taman Nasional Teluk Cendrawasih. Penelitian Hutan, 640, 18-25.

Pratama, V. D., Sukandar, Sunardi, \& Abidin, Z. (2020). Penerapan Teknologi Penetas Telur Penyu Otomatis (Maticgator) di Konservasi Penyu Taman Killi-Kili Desa Wonocoyo Kabupaten Trenggalek. 1, 371-377.

Undang-Undang Republik Indonesia Nomor 5 Tahun 1990 Tentang Konservasi Sumber Daya Alam Hayati Dan Ekosistemnya, Pasal 21 ayat (2) huruf e. 